\title{
Detection of Anaplasma phagocytophilum in Ixodes ricinus ticks from Norway using a realtime PCR assay targeting the Anaplasma citrate synthase gene glt $A$
}

\author{
Anna J. Henningsson 1*, Dag Hvidsten², Bjørn-Erik Kristiansen ${ }^{3}$, Andreas Matussek', Snorre Stuen ${ }^{4}$ \\ and Andrew Jenkins ${ }^{5}$
}

\begin{abstract}
Background: A TaqMan real-time PCR assay targeting the Anaplasma citrate synthase gene, gltA, was developed and used for detection of Anaplasma phagocytophilum in 765 Ixodes ricinus ticks collected from dogs and cats in northern Norway $(n=669)$ and Telemark county in southern Norway $(n=96)$.
\end{abstract}

Results: Among the ticks from northern Norway the prevalence of $A$. phagocytophilum was $3.0 \%$, while the prevalence in southern Norway was $2.1 \%(p=0.63)$. The gltA PCR assay showed a high analytical sensitivity (30 genomic units) and efficiency (98.5\%), and its utility in clinical diagnostics should be evaluated in future studies.

Conclusion: This is the first report of A. phagocytophilum occurrence in ticks collected north of the Arctic Circle in Norway. The prevalence is comparable to that found in Telemark county in southern Norway.

Keywords: Anaplasma phagocytophilum, Ixodes ricinus, TaqMan realtime PCR, Norway, gltA, Prevalence

\section{Background}

Anaplasma phagocytophilum is an obligate intracellular rickettsial pathogen transmitted by Ixodes ticks [1]. The bacterium is a well-documented pathogen in veterinary medicine, causing tick-borne fever (TBF) in domestic ruminants and horses [2,3]. The first verified cases of human granulocytic anaplasmosis (HGA) were reported from the USA in 1994 [4, 5], and the first verified European cases were reported from Slovenia in 1997 [6]. HGA cases have been reported from southern Norway and there is serological evidence of Anaplasma endemicity [7-10]. The pathogen is also prevalent in Norwegian livestock [11], and serological findings in cattle have indicated the presence of $A$. phagocytophilum in Nordland county in northern Norway [12]. Anaplasma phagocytophilum is a possible emerging tick-borne pathogen in

\footnotetext{
* Correspondence: anna.jonsson.henningsson@rj.se

'Department of Clinical Microbiology, Division of Medical Services, County Hospital Ryhov, Jönköping, Sweden

Full list of author information is available at the end of the article
}

northern Norway, but reports on human disease are lacking.

The prevalence of $A$. phagocytophilum infection in the European tick Ixodes ricinus varies in different areas and between developmental stages of the tick [13]. In Norway, recent studies indicate a prevalence in hostseeking I. ricinus of $1.4 \%$ to $19.4 \%$ with great regional differences $[9,14,15]$.

In vitro cultivation and blood smear microscopy are difficult and cumbersome methods for detection of $A$. phagocytophilum in clinical samples, and therefore clinical diagnostics is mainly based on serology and PCR methods [16]. Major advantages of PCR methods are rapid test results, high sensitivity and the possibility of quantifying pathogen load. Several PCR assays have been described for the detection of $A$. phagocytophilum in clinical samples and in ticks [17-19]. Real time PCR offers gains of rapidity and quantitativity and runs in a closed-system format, which eliminates risks of carry-over contamination. The A. phagocytophilum gene gltA codes for an essential housekeeping enzyme, citrate synthase. Mutations in such 
genes are predominantly point mutations that conserve enzyme function and they are not subject to the effects of diversifying selection that may affect surface proteins targeted by the immune system. This makes them attractive targets for phylogenetic studies, making extensive highquality sequence information available. They are less conserved than $16 \mathrm{~s}$ rRNA genes and generally lack secondary structure, which simplifies the design of species-specific PCR.

In this study, we developed a TaqMan real-time PCR assay targeting gltA for the detection of A. phagocytophilum. Using this test, we aimed at extending previous studies at the ticks' northern distribution limit by investigating the prevalence of $A$. phagocytophilum in I. ricinus ticks collected during a three-year period from different locations in northern and southern Norway.

\section{Methods}

\section{Study area and design}

Collection of ticks from dogs and cats was previously described [20, 21]. Briefly, during 2009, 28 veterinary clinics in the three northernmost Norwegian counties of Nordland, Troms and Finnmark $(n=23)$, and in the southern county of Telemark $(n=5)$ collected ticks from dogs and cats [20]. In 2010-2011, veterinary clinics in districts in northern Norway (Nordland, $n=7$; Troms, $n=1$ ) collected ticks from dogs and cats for one season each (Fig. 1) [21]. For each tick delivery, data concerning number of ticks, the geographical origin and kind of source (dog, cat or other sources) was collected. Ticks were placed in plastic tubes containing $1 \mathrm{~mL}$ to $3 \mathrm{~mL} 70 \%$ ethanol and kept at $4^{\circ}$ to $8{ }^{\circ} \mathrm{C}$ until analysis. The collected ticks were examined by stereo light microscopy for determination of species and instar. Only I. ricinus ticks were included. Ticks from dogs or cats that had been outside the study areas during the preceding ten days were excluded. One tick only was collected by the veterinary clinics in Finnmark, but had to be excluded due to the pet's recent travel outside the study area. Ticks from other sources than dogs or cats were not included. To avoid prevalence overestimates due to co-feeding [22], the pet source and PCR findings were scrutinised, and if there was a possibility of co-feeding and PCR results were concordant, the ticks were not included.

\section{Nucleic acid extraction and design of A. phagocytophilum PCR}

Nucleic acid extraction was done as previously described [20], individually from each tick and stored at $-20{ }^{\circ} \mathrm{C}$ until use.

Multiple sequence alignment [23] of six gltA sequences of $A$. phagocytophilum with a selection of the most similar $g l t A$ sequences from related species $(A$.

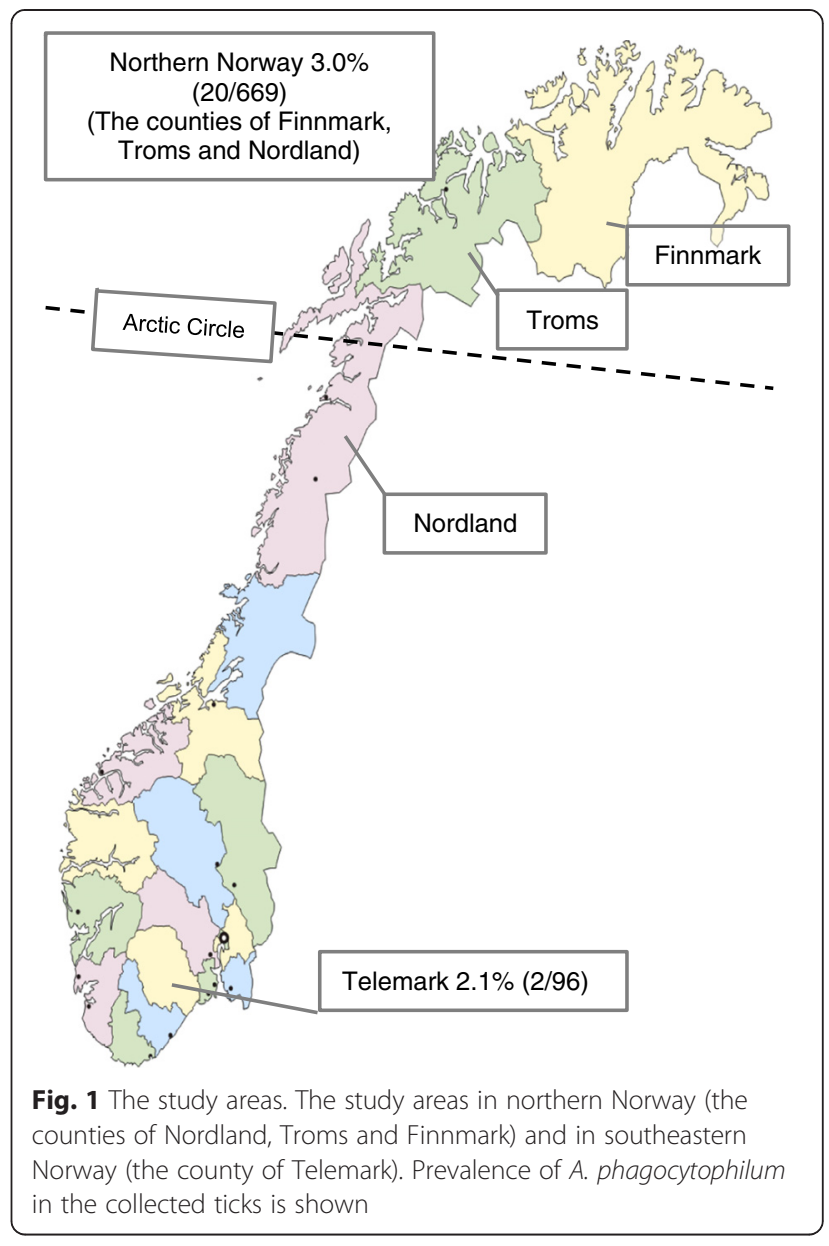

platys, Rickettsia africae, $R$. heilongjiangensis, $R$. principis and Wolbachia DQ266529) identified by BLAST search (http://blast.ncbi.nlm.nih.gov/) revealed a sequence region from $320-435$ in the reference sequence AF304137 that was both highly conserved within $A$. phagocytophilum and highly divergent in related species. Primer-Express (Applied Biosystems, Foster City, CA) was used to design a two-step TaqMan $\mathrm{MGB}^{\circ}$ PCR targeting a 64 bp segment of this region. Table 1 lists the primers, probe and cycling parameters. Every reaction consisted of $25 \mu \mathrm{L}$ containing $12.5 \mu \mathrm{L} 2 \mathrm{x}$ Taqman Universal PCR mastermix (Life Technologies, Waltham, MA, USA), $600 \mathrm{nM}$ of each primer, $150 \mathrm{nM}$ probe, $4.5 \mu \mathrm{L}$ RNAse free water and $5 \mu \mathrm{L}$ DNA. Primers and probe were obtained from Life Technologies. The probe incorporated a stabilising minor groove binder $\left(\mathrm{MGB}^{\circ}\right)$ and was labelled with fluorescein amidite (FAM) and equipped with a dark quencher.

A synthetic plasmid, pAP-GltA, containing the amplicon sequence cloned in pUC57 was obtained from Genscript Corporation (Scotch Plains, NJ). This plasmid was used as a positive control. Serial dilutions of the plasmid 
Table 1 Primers, probes and cycling parameters

\begin{tabular}{lllll}
\hline Name & Sequence & Function & Tm & Concentration \\
\hline ApF & TITGGGCGCTGAATACGAT & Forward Primer & $59^{\circ} \mathrm{C}$ & $300 \mathrm{nM}$ \\
ApR & TCTCGAGGGATGATCTAATAACGT & Reverse Primer & $58^{\circ} \mathrm{C}$ & $300 \mathrm{nM}$ \\
ApM & TGCCTGAAC AAGTTATG & $5^{\prime}$ hydrolysis probe & $69^{\circ} \mathrm{C}$ & $300 \mathrm{nM}$ \\
\hline
\end{tabular}

Cycling parameters: $50{ }^{\circ} \mathrm{C}, 10 \mathrm{~min} ; 95^{\circ} \mathrm{C}, 2 \mathrm{~min} ;\left\{95^{\circ} \mathrm{C}, 15 \mathrm{~s} ; 60^{\circ} \mathrm{C}, 60 \mathrm{~s}\right\} \times 40$ cycles

The initial $50^{\circ} \mathrm{C}$ incubation is an optional step allowing the decontaminating action of uracyl nucleoside glycosylase (UNG), if present

were used to determine analytical sensitivity and as a quantitation standard.

\section{Statistics}

Differences in A. phagocytophilum prevalence were analysed by Chi-Square test, $p<0.05$ was regarded as significant.

\section{Ethics}

No ethical approval was required for this study since removal of ticks was part of routine care of the pets.

\section{Results \\ Collected ticks}

In total, 765 I. ricinus ticks were collected; 669 from northern Norway (Nordland $n=647$, Troms $n=22$, Finnmark $n$ $=0)$ and 96 from Telemark county in southern Norway. Four hundred-and-sixty-three $(61 \%)$ were detached from dogs $(n=330)$, and $302(39 \%)$ from cats $(n=190)$ (Table 2$)$. Of the collected ticks, 690 were adult females, of which approximately $90 \%$ were moderately to fully engorged; there were 69 adult males, four nymphs and two ticks of undetermined instar.

\section{In silico evaluation of the PCR test}

A BLAST search conducted in June 2015 (http:// blast.ncbi.nlm.nih.gov/) using the entire 64 bp amplicon sequence gave 85 hits to $A$. phagocytophilum gltA sequences. Fourty-eight sequences showed $100 \%$ similarity to the primer and probe sequences, 31 showed a single mismatch in the reverse primer

Table 2 Collected ticks, their origin and prevalence of Anaplasma phagocytophilum

\begin{tabular}{|c|c|c|c|}
\hline & $\begin{array}{l}\text { No. of } A \text {. } \\
\text { phagocytophilum- } \\
\text { infected ticks (\%) }\end{array}$ & $\begin{array}{l}\text { No. of } A \text {. } \\
\text { phagocytophilum- } \\
\text { infected ticks } \\
\text { from dogs (\%) }\end{array}$ & $\begin{array}{l}\text { No. of } A \text {. } \\
\text { phagocytophilum- } \\
\text { infected ticks } \\
\text { from cats (\%) }\end{array}$ \\
\hline Troms & $2 / 22(9.1)$ & $2 / 10(20)$ & $0 / 12(0)$ \\
\hline Nordland & 18/647 (2.8) & $11 / 361(3.0)$ & $7 / 286(2.4)$ \\
\hline $\begin{array}{l}\text { Total } \\
\text { North Norway }\end{array}$ & $20 / 669(3.0)$ & 13/371 (3.5) & $7 / 298(2.3)$ \\
\hline Telemark & 2/96 (2.1) & 2/92 (2.2) & $0 / 4(0)$ \\
\hline Total & $22 / 765$ (2.9) & $15 / 463(3.2)$ & $7 / 302(2.3)$ \\
\hline
\end{tabular}

and one (R33, JX841253) showed single mismatches in central parts of both primer sequences. Both these mismatches will result in stable, non-canonical G:T basepairs and are unlikely to appreciably affect PCR sensitivity. Five sequences, all of far-eastern origin, were highly divergent and are unlikely to be detected efficiently, if at all. A comparison of the sequences is shown in Fig. 2. Hits to non-A. phagocytophilum sequences were short and/or highly mismatched. A high degree of specificity for A. phagocytophilum is thus expected.

Analytical sensitivity and efficiency of the gltA PCR assay Analysis of a 10x serial dilution of pAP-GltA from $3.10^{6}$ to 30 genomic units $(\mathrm{GU}) / 5 \mu \mathrm{L}$ (in duplicate) using the analysis software of the Applied Biosystems StepOne genetic analyzer gave a PCR efficiency of $98.5 \%$ based on the slope of the standard curve of the Cq values (coefficient of determination, $\left.\mathrm{R}^{2}=0.998\right)$. Testing of 10 replicates of $30 \mathrm{GU}$ ( $9 / 10$ positive) and $3 \mathrm{GU}$ (5/10 positive) gave a cut-off of $30 \mathrm{GU}$ (Minimum Information for Publication of Quantitative Real-Time PCR Experiments (MIQE) Guidelines) [24].

\section{A. phagocytophilum prevalence and geographical distribution}

The overall prevalence of $A$. phagocytophilum in the collected ticks was $2.9 \%(22 / 765)$ (Table 2). Of the ticks collected from dogs and cats $3.2 \%$ (15/463) and $2.3 \%$ (7/302), were positive for $A$. phagocytophilum, respectively $(p=0.46)$.

Among the adult female ticks, $2.8 \%$ (19/690) were positive for A. phagocytophilum, while $4.3 \%$ (3/69) of the adult male ticks were positive $(p=0.45)$. None of the four collected nymphs were positive for $A$. phagocytophilum.

Of the ticks collected in the three northernmost counties in Norway, $3.0 \%(20 / 669)$ were positive for $A$. phagocytophilum (Nordland $2.8 \%$ (18/647); Troms $9.1 \%$ (2/22); the tick collected in Finnmark could not be included due to the pet's recent stay outside the study area. Of the ticks collected in Telemark county, $2.1 \%(2 / 96)$ were positive for A. phagocytophilum (Fig. 1). There was no significant difference in $A$. phagocytophilum prevalence in ticks collected in northern Norway compared to ticks collected in Telemark county $(p=0.63)$. 


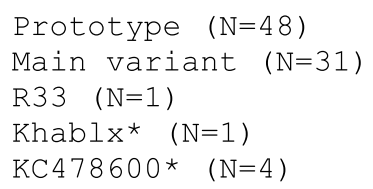

Fig. 2 The PCR target region. Multiple sequence alignment of variants of the PCR target sequence. The positions of the primers and probe targets are highlighted in green and yellow respectively. Dots indicate identity to the prototype sequence. Variant nucleotides are shown as highlighted letters. Blue highlighting indicates variations that make non-destabilizing G:T base pairing with the primer/probe. Red highlighting indicates destabilizing mismatches. Variant nucleotides outside the primer/probe targets are highlighted in grey. ${ }^{*}$ : isolates of exclusively far-eastern origin

\section{Discussion}

In this study we developed a real-time PCR assay targeting $g l t A$ with the purpose of direct detection of $A$. phagocytophilum in ticks. By using a large collection of ticks we give new insights into the epidemiology of $A$. phagocytophilum in ticks in northern Norway in relation to a southern Norwegian county (Telemark). We report here, for the first time, the presence of A. phagocytophilum in feeding ticks collected north of the Arctic Circle in Norway.

Previous studies have demonstrated the presence of $I$. ricinus in northern Norway as well as a high prevalence of Borrelia burgdorferi sensu lato in ticks in the region around the Arctic Circle [15, 20, 21]. Serological studies in two sheep flocks in Brønnøy found a high seroprevalence against $A$. phagocytophilum; $97 \%$ and $100 \%$, respectively (Stuen et al., unpublished data). In addition, a serological study in dogs from northern Norway found a seropositivity of $3 \%(4 / 120)$; three of the dogs were from Brønnøy [25]. The presence of A. phagocytophilum has recently been reported in a smaller number of I. ricinus ticks collected by flagging vegetation in Brønnøy in the county of Nordland [15]. We found an overall prevalence of A. phagocytophilum in feeding ticks of $3.0 \%$ in northern Norway, which is about the same prevalence as we found in Telemark county in southern Norway, and also comparable to the prevalence in I. ricinus in more southern parts of Europe [13]. The majority of the ticks in this study were collected in Nordland county (85\%), which includes the archipelago of Brønnøy, recognised for its high tick abundance [21]. Climate, day length, habitat, mixture of hosts, and host abundance seem to be favourable for I. ricinus in this area, and apparently also for maintenance of $A$. phagocytophilum in the tick population.

Anaplasma phagocytophilum is internationally regarded as an emerging tick-borne pathogen, and areas of endemicity include parts of North America, Europe and Asia [26]. These regions correspond to areas where the appropriate tick vectors are found (I. ricinus in Western Europe, I. persulcatus in Eastern Europe and Asia, I. scapularis and I. pacificus in Eastern and Western USA respectively) [27]. Tick population density and geographical distribution are affected by changes in climate, vegetation and host abundance [28], and continuous surveillance of ticks and tick-borne pathogens at their distribution limits are important for early detection of altered risk scenarios and threats to public health. Although increasingly detected, symptomatic HGA still appears to be rather rare in Europe [17, 29], as opposed to the situation in the USA where HGA is a notifiable disease with increasing incidence [30]. However, human seroprevalence in Europe varies between 2-28 \% [29]. It is unclear whether the discrepancy between the seroprevalence and the low number of symptomatic cases results from underdiagnosis of HGA, asymptomatic serologic reactions, reduced virulence of circulating $A$. phagocytophilum strains in Europe or even infections that cause cross-reactive serologic responses [27]. In any case, $A$. phagocytophilum is endemic in Europe where it is the most widespread tick-borne pathogen in animals [31], and should therfore also be regarded as a potentially emerging human pathogen. Tick-exposed patients presenting with fever, leukopenia and elevated serum transaminases should have HGA included in the differential diagnoses [26].

The PCR method developed showed a high analytical sensitivity (30 GU) and efficiency (98.5\%). Based on the in silico analysis, the test is expected to be highly specific. It is rapid, and the results were found to be unambiguous and straightforward to interpret. We found this PCR assay to be useful for detection of A. phagocytophilum in ticks, and it may also be useful in clinical diagnostics in both human and veterinary medicine, but further evaluation of the method using clinical specimens will be needed.

In silico testing showed that 79/85 (93\%) of Anaplasma phagocytophilum gltA sequences are highly homologous to the primers and probe and will be efficiently detected. The same applies to a slightly more divergent sequence represented by isolate R33 (JX841254) [32] which, according to information presented in the sequence file, was detected in reindeer (Rangifer tarandus) imported to France. However, some far-eastern isolates are expected to be detected at low sensitivity, if at all. These include a group represented by strain $\mathrm{KC} 478600$, isolated from a rat (Rattus norvegicus) in southeastern China [33], and a single isolate, Khablx (AY339603), from I. persulcatus in the Russian far east [34]. 


\section{Conclusion}

The present study implies that both humans and pets may contract anaplasmosis also in northern parts of Norway, and that physicians as well as veterinarians need to be aware of the disease. The PCR assay targeting gltA performed well, and may be useful in clinical diagnostics in the future, but may fail to detect certain fareastern isolates.

\section{Competing interests}

The authors declare that they have no competing interests.

\section{Authors' contributions}

AJH analysed the data and drafted the manuscript. DH conceived of the study, participated in its design, coordinated the collection of ticks and helped to write the manuscript. BEK participated in the design of the study as well as in data collection. AM and SS participated in the design of the study and helped to draft the manuscript. AJ participated in the planning of the study, designed the PCR assay, participated in data analysis and helped to draft the manuscript. All authors read and approved the final manuscript.

\section{Acknowledgements}

The authors would like to thank Malin Lager and Olaf Dienus, Department of Clinical Microbiology, County Hospital Ryhov, Jönköping, for performing the laboratory work, and Sture Löfgren for valuable help with the manuscript. The primers and probe were designed during a class exercise in PCR primer design for MSc students directed by AJ at Telemark University College. We would like to thank all the students who participated, and particularly Nina Narmoe Egerberg whose primer selection was the basis for the present test. We are in debt to the personnel at the veterinary clinics in northern Norway and Telemark that examined the pets and collected the ticks, and to the pet owners in these regions; without their support this study would not have been realisable. This work was supported by grant SFP912-10 from the Northern Norway Regional Health Authority (Helse Nord RHF), and grant SLS-100221 from the Scandinavian Society of Antimicrobial Chemotherapy, as well as grants from the Division of Medical Services, County Hospital Ryhov, Jönköping.

\section{Author details}

${ }^{1}$ Department of Clinical Microbiology, Division of Medical Services, County Hospital Ryhov, Jönköping, Sweden. ${ }^{2}$ Department of Microbiology and Infection Control, University Hospital of North Norway, Tromsø, Norway. ${ }^{3}$ Research group of host-microbe interactions, Department of Medical Biology, Faculty of Health Sciences, UiT - The Arctic University of Norway, Troms $\varnothing$, Norway. ${ }^{4}$ Department of Production Animal Clinical Sciences, Norwegian University of Life Sciences, Sandnes, Norway. ${ }^{5}$ Department of Environmental and Health Studies, Telemark University College, Bø, Norway.

\section{Received: 3 March 2015 Accepted: 16 July 2015}

\section{Published online: 01 August 2015}

\section{References}

1. Parola P, Davoust B, Raoult D. Tick- and flea-borne rickettsial emerging zoonoses. Vet Res. 2005;36:469-92.

2. Foggie A. Studies on the infectious agent of tick-borne fever in sheep. J Pathol Bacteriol. 1951;63:1-15. doi:10.1002/path.1700630103.

3. Gribble DH. Equine ehrlichiosis. J Am Vet Med Assoc. 1969;155:462-9.

4. Bakken JS, Dumler JS, Chen SM, Eckman MR, Van Etta LL, Walker DH. Human granulocytic ehrlichiosis in the upper Midwest United States. A new species emerging? JAMA. 1994;272(3):212-8.

5. Chen SM, Dumler JS, Bakken JS, Walker DH. Identification of a granulocytotropic Ehrlichia species as the etiological agent of human disease. J Clin Microbiol. 1994;32:589-95.

6. Petrovec M, Lotric Furlan S, Zupanc TA, Strle F, Brouqui P, Roux V, et al. Human disease in Europe caused by a granulocytic Ehrlichia species. J Clin Microbiol. 1997:35:1556-9.

7. Bakken JS, Krueth J, Tilden RL, Dumler JS, Kristiansen BE. Serological evidence of human granulocytic ehrlichiosis in Norway. Eur J Clin Microbiol Infect Dis. 1996;15(10):829-32.
8. Stuen S, Bergström K. Serological investigation of granulocytic Ehrlichia infection in sheep in Norway. Acta Vet Scand. 2001;42(3):331-8.

9. Mysterud A, Easterday WR, Qviller L, Viljugrein H, Ytrehus B. Spatial and seasonal variation in the prevalence of Anaplasma phagocytophilum and Borrelia burgdorferi sensu lato in questing Ixodes ricinus ticks in Norway. Parasit Vectors. 2013;6(1):187.

10. Hjetland R, Henningsson AJ, Vainio K, Dudman SG, Grude N, Ulvestad E. Seroprevalence of antibodies to tick-borne encephalitis virus and Anaplasma phagocytophilum in healthy adults from western Norway. Infect Dis (Lond). 2015:47(1):52-6. 2014.

11. Stuen S, Bergström K. [Human anaplasmosis - a hidden disease in Norway?]. Tidsskr Nor Laegeforen. 2008;128(22):2579-81. Human anaplasmose - en skjult sykdom i Norge?

12. Stuen S, Solli Oppegaard A, Bergström K, Moum T. Anaplasma phagocytophilum infection in North Norway. The first laboratory confirmed case. Acta Vet Scand. 2005;46:167-71.

13. Stuen S, Granquist EG, Silaghi C. Anaplasma phagocytophilum - a widespread multi-host pathogen with highly adaptive strategies. Front Cell Infect Mircrobiol. 2013;2:31. doi:10.3389/fcimb.2013.00031.

14. Rosef O, Radzijevskaja J, Paulauskas A, Haslekås C. The prevalence of Anaplasma phagocytophilum in host-seeking Ixodes ricinus ticks in Norway. Clin Microbiol Infect. 2009;15 Suppl 2:43-5. doi:10.1111/j.1469-0691.2008.02169.x.

15. Soleng A, Kjelland V. Borrelia burgdorferi sensu lato and Anaplasma phagocytophilum in Ixodes ricinus ticks in Brønnøysund in northern Norway. Ticks Tick Borne Dis. 2013;4(3):218-21.

16. Dong J, Olano JP, McBride JW, Walker DH. Emerging pathogens: challenges and success of molecular diagnostics. J Mol Diagn. 2008;10(3):185-97.

17. Blanco JR, Oteo JA. Human granulocytic ehrlichiosis in Europe. Clin Microbiol Infect. 2002:8:763-72.

18. Brouqui P, Bacellar F, Baranton G, Birtles RJ, Bjoersdorff A, Blanco JR, et al ESCMID Study Group on Coxiella, Anaplasma, Rickettsia and Bartonella; European Network for Surveillance of Tick-Borne Diseases. Guidelines for the diagnosis of tick-borne bacterial diseases in Europe. Clin Microbiol Infect. 2004;10:1108-32

19. Massung RF, Slater KG. Comparison of PCR assays for detection of the agent of human granulocytic ehrlichiosis. Anaplasma Phagocytophilum J Clin Micribiol. 2003;41:717-22.

20. Jenkins A, Hvidsten D, Matussek A, Lindgren PE, Stuen S, Kristiansen BE. Borrelia burgdorferi sensu lato in Ixodes ricinus ticks from Norway: evaluation of a PCR targeting the chromosomal flab gene. Exp Appl Acarol. 2012;58:431-9.

21. Hvidsten D, Stuen S, Jenkins A, Dienus O, Olsen RS, Kristiansen BE, et al. Ixodes ricinus and Borrelia prevalence at the Arctic Circle in Norway. Ticks Tick Borne Dis. 2014;5(2):107-12

22. Randolph SE, Gern L, Nuttall PA. Co-feeding ticks: epidemiological significance for tick-borne pathogen transmission. Parasitol Today. 1996;12:472-9.

23. Larkin MA, Blackshields G, Brown NP, Chenna R, McGettigan PA, McWilliam $H$, et al. Clustal W and Clustal $X$ version 2.0. Bioinformatics. 2007;23(21):2947-8.

24. Bustin SA, Benes V, Garson JA, Hellemans J, Huggett J, Kubista M, et al. The MIQE guidelines: minimum information for publication of quantitative real-time PCR experiments. Clin Chem. 2009;55:611-22.

25. Meldal H, Stuen S. Flått og flåttbårne sjukdommer hos hund i Nordland. Norsk Veterinærtidsskrift. 2012;6:427-33.

26. Dumler JS, Madigan JE, Pusterla N, Bakken JS. Ehrlichioses in humans: epidemiology, clinical presentation, diagnosis, and treatment. CID. 2007;45 Suppl 1:S45-51.

27. Dumler JS, Choi KS, Garcia-Garcia JC, Barat NS, Scorpio DG, Garyu JW, et al. Human granulocytic anaplasmosis and Anaplasma phagocytophilum. Emerg Infect Dis. 2005;11(12):1828-34.

28. Rizzoli A, Silaghi C, Obiegala A, Rudolf I, Hubalek Z, Földvari G, et al. Ixodes ricinus and its transmitted pathogens in urban and peri-urban areas in Europé: new hazards and relevance for public health. Front Public Health. 2014;2:251.

29. Strle F. Human granulocytic ehrlichiosis in Europe. Int J Med Mictobiol. 2004;293 Suppl 37:27-35.

30. Centers for Disease Control and Prevention. Summary of notifiable diseases - United States. MMWR 2011;60:1-117 (cited January 2015); available from http://www.cdc.gov/mmwr/mmwr_nd/.

31. Stuen S. Anaplasma phagocytophilum - the most widespread tick-borne infection in animals in Europe. Vet Res Commun. 2007;31 Suppl 1:79-84. 
32. Inokuma H, Brouqui P, Drancourt M, Raoult D. Citrate synthase gene sequence: a new tool for phylogenetic analysis and identification of Ehrlichia. J Clin Microbiol. 2001;39(9):3031-9.

33. Zhao XG, Hao L, Zhang YY, Jiang JF, Liu W, Cao WC. Dual infection with Anaplasma phagocytophilum and Babesia microti in a Rattus norvegicus. China Ticks Tick Borne Dis. 2013;4:399-402.

34. Dumler JS, Barbet AF, Bekker CP, Dasch GA, Palmer GH, Ray SC, et al. Reorganization of genera in the families Rickettsiaceae and Anplasmataceae in the order Rickettsiales: unification of some species of Ehrlichia with Anaplasma, Cowdria with Ehrlichia and Ehrlichia with Neorickettsia, description of six new species combinations and designation of Ehrlichia equi and "HGE agent" as subjective synonyms of Ehrlichia phagocytophila. Int J Syst Evol Microbiol. 2001;51(Pt6):2145-65.

\section{Submit your next manuscript to BioMed Central and take full advantage of:}

- Convenient online submission

- Thorough peer review

- No space constraints or color figure charges

- Immediate publication on acceptance

- Inclusion in PubMed, CAS, Scopus and Google Scholar

- Research which is freely available for redistribution 